\title{
Risk factors associated with human papillomavirus infection in two populations from Rio de Janeiro, Brazil
}

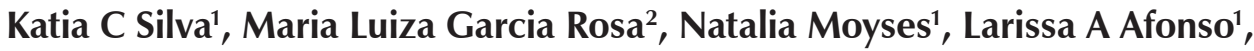 \\ Ledy HS Oliveira', Silvia MB Cavalcanti ${ }^{1 /+}$
}

${ }^{2}$ Departamento de Epidemiologia e Bioestatística, Hospital Universitário Antônio Pedro 'Departamento de Microbiologia e Parasitologia, Instituto Biomédico, Universidade Federal Fluminense, R. Prof. Ernani Melo 101, sala 321, 24210-130 Niterói, RJ, Brasil

We investigated human papillomavirus (HPV) infection in two female populations from diverse socio-economic strata from the state of Rio de Janeiro and we also investigated the possible co-factors related to infection and the progression to cancer. In Group I, the reference group of this study, $10.7 \%$ of the patients presented HPV infection, as detected by generic PCR, while in Group II (low socio-demographic conditions) HPV was detected in $31.1 \%$ of the samples. HPVI6 was the most prevalent virus type found in both Groups I and II (5.3\% and 10\%, respectively), followed by HPV 18 (1.3\% and 4.7\%, respectively). Although only a small sample was analysed, we detected differences among the groups regarding the rates of HPV infection, HPV types, age, ethnicity, familial income, schooling, marital status, parity, tobacco smoking and oral contraceptive use. For Group I, the Papanicolaou test was the most powerful independent factor associated with HPV status, followed by an age of under 30 years old, the number of sexual partners and black ethnicity. Our data are in agreement with the co-factors that are typically described for the developed world. For Group II, the Pap test was also the most relevant variable that was analysed, but the history of other sexually transmitted diseases and the use of alcohol were additional factors that were implicated in infection. These findings point out the need for the development of general and specific strategies for HPV screening of all Brazilian women.

Key words: HPV - risk factors - age - sexual partners - PCR - Papanicolaou

The World Health Organization presents data placing cervical cancer as the second most prevalent malignant neoplasia in women worldwide, with nearly 500,000 new cases and 250,000 deaths each year (Baseman \& Koutsky 2005). Most of the cases arise in the developing world, where organised screening programmes using the Papanicolaou preventive test have not been successfully implemented (Jones 1999). In Brazil, cervical cancer is the second most prevalent cause of death from cancer (INCA 2008). In the last two decades, malignant transformation has progressively been detected in younger women (Pereira et al. 2007).

Large epidemiological and prospective studies conducted in various countries have shown that the risk of developing cervical cancer is strongly associated with the presence and persistence of high-risk genital papillomavirus types (Bosh \& San José 2003). Nevertheless, it has been established that human papillomavirus (HPV) infection is the most important, but not the exclusive, risk factor to cervical cancer. Hence, epidemiological investigations have focused on the role of cofactors associated with cancer progression (Baseman \& Koutsky 2005).

Financial support: Faperj (E26/170-271/2006)

+ Corresponding author: silviacavalcanti@vm.uff.br

Received 16 February 2009

Accepted 4 June 2009
Brazil is a large country, representing diverse socioeconomical conditions in different regions and states. Cancer incidences also vary extensively, ranging from $26.7 / 10^{5}$ in the South to $43.8 / 10^{5}$ in the North (INCA 2008). Even within the Rio de Janeiro metropolitan area, we can find a portion of the population in a high urban development index and another portion of the population living under the poverty line.

The literature has already indicated that social and economic differences determine diverse profiles in cancer outcome. Additionally, important co-factors are related to cancer, such as sexual behaviour, the number of years of schooling and familial income, among others. However, little is known about these co-factors in relation to the risk of HPV infection (Cuschieri et al. 2004). It is also important to note that most of the previously published Brazilian research has focused on women patients who attended public health clinics and that this group presented high HPV frequencies (Cavalcanti et al. 2000, Oliveira et al. 2007, Pereira et al. 2007). Little is known about middle class female groups, but lower levels of HPV infection might be expected (Syrjanen et al. 2003, Naud et al. 2006). The aim of our study was to evaluate HPV frequency and to determine if socioeconomic differences are related to the frequency of HPV infections in two different populations. Finally, we aimed to verify whether or not the cancer co-factors are present in different degrees. Thus, we investigated two populations of females, who attended either a private or a public gynaecological service, from the state Rio de Janeiro. Prophylactic vaccines for HPV infection 
are now a reality, but since geographical variations in the prevalence of HPV types and co-factors have been documented worldwide (Lepique et al. 2009), further knowledge of the epidemiological data regarding HPV infection in our country may assist health authorities in planning local prophylactic and therapeutic strategies of cancer control.

\section{PATIENTS, MATERIALS AND METHODS}

Study design - This was a cross-sectional study conducted in order to verify HPV infection rates in two female populations. The sample size was determined according to the female population from Maricá and Itaboraí (approx. 70,000 adult women). The expected HPV prevalence for Group I and Group II ranged from $10-25 \%$, respectively. We also evaluated the co-factors related to the risk of HPV infection and to cancer outcome. The study population included 150 women who attended a private gynaecological clinic from the Município de Maricá (Group I - reference group, minor risk) and 150 women who attended the Policlínica Francisco da Cruz Nunes, Município de Itaboraí (Group II - major risk), from January-December 2005. The women were subjected to a routine exam and were randomly selected for the study. The cervical smears were collected with a cervical cytobrush and were transported in Tris-EDTA buffer and stored at $-20^{\circ} \mathrm{C}$.

Questionnaire - A self-administered questionnaire about the demographic data and medical history was answered by all of the women enrolled in this study, following informed consent. All of the women were then interviewed with respect to their reproductive and sexual life variables. The women with a recent history of treatment of lesions associated with HPV, conisation or hysterectomy were excluded. The medical services from the Universidade Federal Fluminense adopted a standard questionnaire that was then applied in this study. The study protocol was approved by the Ethical Committee of the Universidade Federal Fluminense.

Cytologic test - The Papanicolaou-tested smears were classified as normal for a normal epithelium, inflammatory for minor alterations of cells, low grade squamous intraepithelial lesions (LSIL) for low grade neoplasia, high grade squamous intraepithelial lesions (HSIL) for moderate/severe neoplasia, invasive cancer and ASCUS for atypical squamous cells of undetermined significance.

DNA extraction - The samples were incubated for $4 \mathrm{~h}$ at $50^{\circ} \mathrm{C}$ in digestion buffer $(10 \mathrm{mM}$ TRIS-HCl pH 8.3, $1 \mathrm{mM}$ EDTA pH $8.0,0.5 \%$ Tween- $20,400 \mu \mathrm{g} / \mathrm{mL}$ proteinase K). DNA was extracted with phenol-chloroformisoamyl alcohol, precipitated with $0.3 \mathrm{M}$ sodium acetate and three volumes of $100 \%$ ice cold ethanol, washed with $70 \%$ ethanol, air dried and resuspended in $50 \mu \mathrm{L}$ of sterile water.

$H P V$ detection by the polymerase chain reaction $(P C R)$ - Consensus primers, MY09/11, which amplify 450 bp DNA sequences within the L1 region of HPV, were used to detect generic HPV DNA. The amplification was carried out in a $50 \mu \mathrm{L}$ reaction mixture (1X
PCR buffer, $200 \mu \mathrm{M}$ dNTPs, $1.5 \mathrm{mM} \mathrm{MgCl}_{2}, 50 \mathrm{pmol}$ of each primer, $0.25 \mathrm{U}$ unit of Taq polymerase and $5 \mu \mathrm{L}$ of sample) as described elsewhere (Pereira et al. 2007). The $\beta$-actin primers were used as an internal control. PCR products were analysed on a $1.3 \%$ agarose gel with ethidium bromide staining for visualisation of DNA under an ultraviolet light.

HPV typing - HPV typing was done by PCR amplification with primers from the E6 gene DNA sequences of HPV 6, 11,16, 18, 31, 33, 35 and 58 (Pereira et al. 2007).

Statistical analysis - A data bank including the demographic and behavioural factors was generated and analysed using the EPInfo 2004 statistical software package (Center for Disease Control and Prevention, Atlanta, EUA, 2004). The biological, socio-economic and demographic differences were compared through Chi-square tests with a Yates correction. The significance level of tests (p) was set at 0.05 . The association between exposure and outcome was expressed by means of prevalence ratios (PR) (Coutinho et al. 2008).

\section{RESULTS}

The groups that were analysed were composed of population cohorts attended at their annual preventive cytological test.

The average age of participants was 33 years, ranging from 14-79 years old. The profiles of the demographic and socio-economic characteristics of the two studied groups are presented in Table I. Analysis revealed that there were statistically significant differences regarding mean age of the female population, ethnicity, familial income, schooling, marital status, menarche, parity, tobacco smoking and use of oral contraceptive (OC use).

Regarding HPV infection, we found that in Group I, HPV DNA was detected in $10.7 \%$ of the patients $(16 / 150)$ while in Group II, the HPV DNA was detected in $31.1 \%$ (46/150) of the patients. HPV 16 was the most prevalent type found in both groups (5.3\% and $10 \%$, respectively), followed by HPV 18 (1.3\% and 4.7\%, respectively). The high-risk types, 33 and 58 , were both found at $0.7 \%$ in Group I and at $4 \%$ and $2 \%$, respectively, in Group II. Types 6,11 and 35 were only found in Group II $(2 \%$, $0.7 \%$ and $2 \%$, respectively) and HPV 31 was not detected. Multiple infections were found in $0.7 \%$ of the samples from Group I and in 3.3\% of the samples from Group II. Both of the groups presented MY positive samples (4 samples in Group I and 12 samples in Group II) that remained untyped by PCR specific primers (Table II).

As presented in Table II, the patients from Group II had a 1.72-fold greater chance of being infected by HPV $(p<0.001)$. This group also had a 2.1-fold greater chance of being infected by the high-risk viruses. The cytological test results showed that Group I had a low rate of HSIL (1.3\%) while Group II had an $8.7 \%$ rate of HSIL. The statistical analysis demonstrated that there was a 1.77-fold greater chance of a woman presenting HSIL if she belonged to Group II $(p<0.001)$, when compared to women from Group I.

The bivariate-analysis showed that there were specific variables associated with HPV infection in these dis- 


\section{TABLE I}

Demographic and socio-economic factors evaluated for studied female groups

\begin{tabular}{|c|c|c|c|}
\hline Variables & $\begin{array}{c}\text { Group I } \\
\mathrm{n}(\%)\end{array}$ & $\begin{array}{l}\text { Group II } \\
\text { n }(\%)\end{array}$ & $\mathrm{p}$ value \\
\hline \multicolumn{4}{|l|}{ Age } \\
\hline 30 years or more & $76(50.7)$ & $100(66.7)$ & \multirow[t]{2}{*}{0.007} \\
\hline-30 years & $74(49.3)$ & $50(33.3)$ & \\
\hline \multicolumn{4}{|l|}{ Ethnic group } \\
\hline Non black & $146(97.3)$ & $120(80)$ & \multirow[t]{2}{*}{$<0.001$} \\
\hline Black & $4(2.7)$ & $30(20)$ & \\
\hline \multicolumn{4}{|l|}{ Familiar income } \\
\hline +2 minimum salaries & $118(78.7)$ & $45(30)$ & \multirow[t]{2}{*}{$<0.001$} \\
\hline 0-2 minimum salaries & $31(21.3)$ & $104(70)$ & \\
\hline \multicolumn{4}{|l|}{ Schooling } \\
\hline More than eight years/college & $118(78.7)$ & $46(30.7)$ & \multirow[t]{2}{*}{$<0.001$} \\
\hline Illiterate/less than eight years & $32(21.3)$ & $104(69.3)$ & \\
\hline \multicolumn{4}{|l|}{ Marital status } \\
\hline Married/with partner & $82(55)$ & $101(67.3)$ & \multirow[t]{2}{*}{0.033} \\
\hline Single, widow, separate & $68(45)$ & $49(32.7)$ & \\
\hline \multicolumn{4}{|l|}{ Sexarca } \\
\hline Till 17 years & $75(50.3)$ & $80(53.4)$ & \multirow[t]{2}{*}{0.687} \\
\hline 18 years or more & $74(49.7)$ & $70(46.6)$ & \\
\hline \multicolumn{4}{|l|}{ Menarca } \\
\hline Till 13 years & $61(40.9)$ & $82(54.7)$ & \multirow[t]{2}{*}{0.024} \\
\hline 14 years or more & $88(59.1)$ & $68(45.3)$ & \\
\hline \multicolumn{4}{|l|}{ Number of partners } \\
\hline One partner & $54(36)$ & $43(28.9)$ & \multirow[t]{2}{*}{0.232} \\
\hline More than one partner & $96(64)$ & $106(71.1)$ & \\
\hline \multicolumn{4}{|l|}{ Parity } \\
\hline Till two children & $112(74.7)$ & $67(44.7)$ & \multirow[t]{2}{*}{$<0.001$} \\
\hline Three or more children & $38(25.3)$ & $83(55.3)$ & \\
\hline \multicolumn{4}{|l|}{ Alcohol use } \\
\hline No & $133(88.6)$ & $128(85.3)$ & \multirow[t]{2}{*}{0.472} \\
\hline Yes & $17(11.3)$ & $22(14.7)$ & \\
\hline \multicolumn{4}{|l|}{ Tobacco smoking } \\
\hline No & $132(88.0)$ & $112(75.2)$ & \multirow[t]{2}{*}{0.007} \\
\hline Yes & $18(12.0)$ & $37(24.8)$ & \\
\hline \multicolumn{4}{|l|}{ Abortion } \\
\hline No & $124(74.4)$ & $116(77.3)$ & 0.312 \\
\hline Yes & $26(25.6)$ & $34(22.7)$ & \\
\hline Familiar history of neoplasia & & & \\
\hline No & $111(74.4)$ & $110(73.3)$ & 0.922 \\
\hline Yes & $38(25.6)$ & $40(26.7)$ & \\
\hline Other sexually transmitted disea & & & \\
\hline No & $133(88.7)$ & $131(87.3)$ & 0.859 \\
\hline Yes & $17(11.3)$ & $19(12.7)$ & \\
\hline Oral anti-contraceptive & & & \\
\hline No & $77(51.3)$ & $117(78)$ & $<0.001$ \\
\hline Yes & $73(48.7)$ & $33(22)$ & \\
\hline Condom use & & & \\
\hline Yes & $15(10)$ & $14(9.3)$ & 1.0 \\
\hline No & $135(90)$ & $136(89.7)$ & \\
\hline
\end{tabular}

statistical test used: Chi-square with continuity correction. 
TABLE II

Statistical analysis of human papillomavirus (HPV) infection, high risk HPV types detected and cytological diagnosis among studied groups

\begin{tabular}{lcccc}
\hline Variables & Group I & Group II & $\begin{array}{c}\text { Prevalence ratio } \\
\text { (IC 95\%) }\end{array}$ & p value \\
\hline HPV & & & $1.72(1.39-2.11)$ & $<0.001$ \\
$\quad$ Negative & $134(89.3)$ & $102(68.9)$ & & \\
$\quad$ Positive & $16(10.7)^{a}$ & $46(31.1)^{b}$ & & \\
High risk HPV & & & & \\
$\quad$ No & $138(92)$ & $115(73.3)$ & & \\
$\quad$ Yes & $12(8.0)^{a}$ & $34(26.7)^{b}$ & & \\
Lesions classified by cytology & & & $1.61-2.56)$ & \\
$\quad$ Normal-inflammatory-ASCUS & $140(93.4)$ & $134(89.9)$ & $0.31(0.12-0.42)$ & 0.14 \\
LSIL-HPV & $8(5.3)$ & $2(1.4)$ & $1.77(1.40-2.24)$ & 0.01 \\
$\quad$ HSIL-cancer & $2(1.3)$ & $13(8.7)$ & \\
\hline
\end{tabular}

statistical test used: Chi-square with continuity correction. $a$ : 16 positive samples presenting 12 high risk types and four untyped viruses; $b$ : 46 positive samples presenting 34 high risk HPV, four low-risk HPV6 and eihgt untyped viruses. ASCUS: atypical squamous cells of undetermined significance; LSIL: low grade squamous intraepithelial lesions.

tinct populations (Table III): in Group I, women younger than 30 years old had a 3.1-fold greater chance of being infected by HPV, as well as black women $(\mathrm{PR}=5.2)$, single, separated or widowed women $(\mathrm{PR}=2.7)$, women with more than one sexual partner $(\mathrm{PR}=8.4)$ and women using oral contraceptives $(\mathrm{PR}=2.3)$. Patients who presented altered results upon cytological testing had a 27.7-fold greater chance of being infected with HPV, compared to women without cytological alterations ( $\mathrm{p}$ $<0.001$ ). Following analysis of Group II, we observed there to be diverse co-factors related to HPV infection: women using alcohol had a 2.5 -fold greater chance of being infected $(p=0.001)$ and tobacco smoking was related to increased risk of infection $(\mathrm{PR}=2.0)$ as well as a history of other sexually transmitted diseases (STD) (PR $=2.7$ ). Early beginning of sexual life gave borderline results $(\mathrm{PR}=1.5)$. The patients presenting altered results upon cytological testing had a 4.3-fold greater chance of being infected with HPV compared to women without cytological alterations $(\mathrm{p}<0.001)$.

\section{DISCUSSION}

In Brazil, cervical cancer remains a major public health problem and it has a marked variation in incidence between the different regions of this vast country. An organised national screening programme exists, but in practice it performs inadequately, except for some local programmes (Oliveira et al. 2007). Our study aimed to verify if women in these different regions are differently exposed to the known risk factors of the disease. As expected, the population variables revealed that the two groups were statistically different regarding the rates of HPV infection, frequency of high grade lesions, age, ethnicity, familial income, schooling, marital status, menarca, parity, tobacco smoking and $\mathrm{OC}$ uses (Table I).
With regard to HPV infection, we detected a strongly different prevalence amongst the groups: $10.7 \%$ of Group I presented HPV infection, while in Group II, nearly $31.1 \%$ presented HPV infection (Table II) $(\mathrm{p}<0.001)$. Naud et al. (2006) found infection prevalence rates of $31.4 \%$, similar to those found for Group II (31.1\%), after studying a similar population, but with a lower mean age (26.6 years old). It is noticeable that estimates of HPV prevalence among women around the world range from 2-44\% (Cushieri et al. 2004, Clifford et al. 2005). Such a wide variation is explained by differences in the age range of the studied groups as well as the sensitivity of the DNA assay for detection of HPV infection (Bosh \& San Jose 2003). Due to our small sample size, the stratification by age significantly compromised the statistical power of the analysis, thus requiring further studies that use an adequate number of samples.

The literature has already documented that cervical cancer is a disease associated with populations that subside in lower developed areas that are associated with poverty and its particular socio-demographic variables (Jones 1999). However, HPV infection, now regarded as an endpoint marker for cervical cancer, is related to socio-demographic factors. The rate of prevalence of HPV infection in reference Group I is considered to be low and this is similar to studies from developed countries, such as Italy, the Netherlands and Spain (Clifford et al. 2005). Thus, this reinforces the idea that higher socio-demographic variables result in better control over not only cervical cancer but also HPV infection and likely other STDs.

Following analysis of the profile of HPV types, we noticed that HPV 16 was the most prevalent type found in both Group I and Group II (5.3\% and 10\%, respectively), followed by HPV 18 (1.3\% and 4.7\%, respectively). Giuliano et al. (2002) and Syrjanen et al. (2003) described 
TABLE III

Prevalence ratio (PR) of HPV infection in relation to biological, socioeconomic and demographic variables

\begin{tabular}{|c|c|c|c|c|c|c|}
\hline \multirow[t]{2}{*}{ Variables } & \multicolumn{3}{|c|}{ Group I } & \multicolumn{3}{|c|}{ Group II } \\
\hline & $\begin{array}{c}\mathrm{HPV} \\
(+)\end{array}$ & $\begin{array}{c}\text { HPV } \\
(-)\end{array}$ & $\begin{array}{c}\mathrm{PR} \\
\text { (IC 95\%) }\end{array}$ & $\begin{array}{c}\mathrm{HPV} \\
(+)\end{array}$ & $\begin{array}{c}\mathrm{HPV} \\
(-)\end{array}$ & $\begin{array}{c}\text { PR } \\
\text { (IC 95\%) }\end{array}$ \\
\hline \multicolumn{7}{|l|}{ Citology } \\
\hline Normal/inflammatory & 3 & 127 & 1.00 & 28 & 100 & 1.00 \\
\hline Ascus/LSIL/HSIL/cancer & 13 & 7 & $27.7(8.8-90.9)$ & 18 & 1 & $4.3(6.1-3.1)$ \\
\hline \multicolumn{7}{|l|}{ Age } \\
\hline 30 years or more & 4 & 72 & 1.00 & 27 & 72 & 1.00 \\
\hline Till 30 years & 12 & 62 & $3.1(1.0-9.1)$ & 19 & 31 & $1.4(0.9-2.3)$ \\
\hline \multicolumn{7}{|l|}{ Ethnic group } \\
\hline Non black & 14 & 132 & 1.00 & 36 & 82 & 1.00 \\
\hline Black & 2 & 2 & $5.2(1.7-15.6)$ & 10 & 20 & $1.1(0.6-1.9)$ \\
\hline \multicolumn{7}{|l|}{ Familiar income } \\
\hline+2 minimum salaries & 12 & 106 & 1.00 & 15 & 30 & 1.00 \\
\hline $0-2$ minimum salaries & 4 & 27 & $1.3(0.4-3.7)$ & 31 & 71 & $0.9(0.6-1.5)$ \\
\hline \multicolumn{7}{|l|}{ Schooling } \\
\hline+8 years/ college & 12 & 106 & 1.00 & 17 & 29 & 1.00 \\
\hline Illiterate/- 8 years & 4 & 28 & $1.2(0.4-3.4)$ & 29 & 73 & $1.3(0.8-2.8)$ \\
\hline \multicolumn{7}{|l|}{ Marital status } \\
\hline Married/ with partner. & 5 & 77 & 1.00 & 31 & 68 & 1.00 \\
\hline Single, widow, separate & 11 & 57 & $2.7(1.0-7.2)$ & 15 & 34 & $1.0(0.6-1.6)$ \\
\hline \multicolumn{7}{|l|}{ Menarca } \\
\hline 14 years or more & 5 & 56 & 1.00 & 25 & 56 & 1.00 \\
\hline Till 12-13 years & 11 & 77 & $1.5(0.6-4.2)$ & 21 & 46 & $1.0(0.6-1.6)$ \\
\hline \multicolumn{7}{|l|}{ Sexarca } \\
\hline 18 years or more & 8 & 67 & 1.00 & 20 & 58 & 1.00 \\
\hline Till 17 years & 8 & 66 & $1.0(0.4-2.6)$ & 26 & 44 & $1.5(0.9-1.4)$ \\
\hline \multicolumn{7}{|l|}{ Number of sexual partners } \\
\hline One partner & 1 & 53 & 1.00 & 11 & 31 & 1.00 \\
\hline More than one partner & 15 & 81 & $8.4(1.2-62.5)$ & 35 & 70 & $1.3(0.7-2.3)$ \\
\hline \multicolumn{7}{|l|}{ Parity } \\
\hline Till two children & 16 & 96 & 1.0 & 24 & 43 & 1.00 \\
\hline Three or more childern & 0 & 38 & - & 22 & 59 & $0.8(0.5-1.2)$ \\
\hline \multicolumn{7}{|l|}{ Alcohol } \\
\hline No & 13 & 120 & 1.00 & 32 & 94 & 1.00 \\
\hline Yes & 3 & 14 & $1.8(0.6-5.7)$ & 14 & 8 & $2.5(1.6-3.9)$ \\
\hline \multicolumn{7}{|l|}{ Tobacoo smoking } \\
\hline No & 14 & 118 & 1.00 & 27 & 83 & 1.00 \\
\hline Yes & 2 & 16 & $1.3(0.3-5.1)$ & 19 & 18 & $2.0(1.5-3.3)$ \\
\hline \multicolumn{7}{|l|}{ Abortion } \\
\hline No & 13 & 111 & 1.00 & 32 & 82 & 1.00 \\
\hline Yes & 3 & 23 & $1.1(0.3-3.6)$ & 14 & 20 & $1.5(0.9-2.4)$ \\
\hline \multicolumn{7}{|l|}{ History of familiar neoplasia } \\
\hline No & 13 & 98 & 1.00 & 32 & 77 & 1.00 \\
\hline Yes & 3 & 35 & $0.7(0.3-2.2)$ & 14 & 25 & $1.2(0.7-2.0)$ \\
\hline \multicolumn{7}{|l|}{ Other STD } \\
\hline No & 13 & 120 & 1.00 & 36 & 93 & 1.00 \\
\hline Yes & 3 & 14 & $1.8(0.6-5.7)$ & 10 & 9 & $2.7(1.2-5.6)$ \\
\hline \multicolumn{7}{|l|}{ Oral contraceptive use } \\
\hline No & 5 & 72 & 1.00 & 35 & 80 & 1.00 \\
\hline Yes & 11 & 62 & $2.3(0.9-6.4)$ & 11 & 22 & $1.1(0.6-1.9)$ \\
\hline Condom use & & & & & & \\
\hline Yes & 2 & 13 & 1.00 & 6 & 8 & 1.00 \\
\hline No & 14 & 121 & $1.3(0.3-5.1)$ & 40 & 94 & $1.4(0.7-2.8)$ \\
\hline
\end{tabular}

statistical test used: Chi square with continuity correction. 
similar results following studies of random populations in Russia and the USA. In Brazil, a large cohort study in São Paulo presented similar results for HPV16, but the prevalence of HPV18 was lower (Villa et al. 2000).

In this study, we investigated the cytological status of the two groups. In both groups, $86 \%$ of the patients presented with a normal Papanicolaou test (Pap test) result or an inflammatory result. However, it is interesting to note that the other $14 \%$ of the results were statistically different: Group II presented 13 high-risk lesions among the 20 altered Pap tests, while Group I presented only two high-grade lesions, among the 20 positive Papanicolaou smears, revealing a significant risk of cancer development in Group II $(\mathrm{p}<0.0001)$ (Table II).

Despite these differences, the most meaningful result was that an altered cytological result for the two studied populations could then be evaluated as a predictor of HPV infection. In Group I, patients who presented altered results upon cytological testing had a 27.7-fold greater chance of being infected with HPV when compared to women without cytological alterations ( $p<$ 0.001 ) and Group II patients had a 4.3 -fold greater chance of being infected with HPV ( $p<0.001)$. In fact, this was expected since the Pap test is a powerful method of clinical detection of active infections caused by HPV in the genital tract. Franco et al. (1999), as well as Naud et al. (2006), also described the Pap test as the most important predictor of HPV infection. In fact, the Pap test may be the only meaningful factor related to risk, since the Pap test can be regarded as an indication that the woman had access to medical care services. Therefore, as expected, these results corroborate the use of the Pap test as an outstanding exam for screening women at risk of HPV infection. The importance of cytology as a marker for cervical cancer has led many authors to reemphasise the relevance of an altered Pap test as an indicator of HPV. Therefore, the combination of cytology and molecular tests are the most important factors described at present for cancer prevention. An alternative study has analysed HPV serology and the cancer biomarkers of proteins p53 and p16, but no agreement on cancer prevention was achieved (Heilman \& Kreinberg 2002).

In our study, due to the small sample size, a multivariate analysis was not performed. Thus, we have to consider the possibility that confounding variables led to altered prevalence results. In addition, other risk factors, such as the number of visits to gynaecological care and the interval between Pap tests, although recorded, were not evaluated in this article due to a great amount of misinformation during interviews and thus the data were discarded as incomplete or controversial.

As described in Table III, a highly significant factor associated with HPV infection in Group I was an age under $30(\mathrm{PR}=3.1)$. Marital status was also frequently associated with infection ( $\mathrm{PR}=2.7)$, as well as ethnicity $(\mathrm{PR}=5.2)$. HPV infection also prevailed in women with more than one sexual partner $(\mathrm{PR}=8.4)$. Several authors have described similar results, especially in regards to the number of lifetime sexual partners (Bauer et al. 1993, Muñoz et al. 1996, Wang et al. 2003, Base- man \& Koutsky 2005). We have chosen the criterion "one sexual partner versus more than one sexual partner" since women with a single long-term sexual partner were less likely to acquire sexually transmitted infections when compared to women who reported more than one partner (Pereira et al. 2007). For group II, a previous history of STD was significantly related to HPV infection $(\mathrm{PR}=2.7)$ and this likely reflects other related risk factors, such as the number of sexual partners. It is important to note that infection by other genital pathogens also contributes to the risk of HPV infection by depressing local immunity. Nevertheless, co-infections in the genital tract can result in complex interactions between the different pathogens and the immune system of the host (Ferenczy et al. 2003), a discussion that is beyond the scope of this study.

A few studies have addressed the risk of smoking and infection and have found a significant correlation, attributed to a local impairment of cell-mediated immunity, but the effect of this was small (Burk et al. 1996, Wang et al. 2003, Stern 2005). In our statistical analysis, we found a significant correlation between the presence of HPV DNA and current smokers ( $\mathrm{PR}=2.0$ ), but further studies concerning the amount of smoking per day are required to elucidate a possible relationship. Alcohol use, not only addiction, was significantly related to HPV occurrence in the genital tract (Table III). As previously proposed by Ho et al. (1988), alcohol use could alter social behaviour, leading to an augmented risk of exposure to STD-causing agents.

The peculiar results that were found for Group II suggested that the analysed co-factors can express the profile of this population, based on alcohol use and history of other STDs. In addition, the high prevalence described may be associated with other borderline variables, such as tobacco smoking, early beginning of sexual life and abortion, among others factors that are usually associated with poorer populations from developing countries. The finding of such diverse conditions and the risk of exposure within the same geographical region, poses a challenge to public health: to develop not only general but also specific strategies for screening all Brazilian women.

\section{REFERENCES}

Baseman JG, Koutsky LA 2005. The epidemiology of human papillomavirus infections. J Clin Virol 32S: 16-24.

Bauer HM, Hildesheim A, Schiffman MH, Glass AG, Rush BB, Scott DR 1993. Determinants of genital human papillomavirus infection in low risk women in Portland, Oregon. Sex Trans Dis 20: $274-278$.

Bosch FX, Sanjosé S 2003. Human papillomavirus and cervical cancer-burden and assessment of causality. Monographs J Nat Cancer Inst 31: 3-13.

Burk RD, Ho GYF, Beardsley L, Lempa M, Peters M, Bierman R 1996. Sexual behavior and partner characteristics are the predominant risk factors for genital human papillomavirus infection in young women. $J$ Infect Dis 174: 679-689.

Cavalcanti SMB, Zardo LG, Oliveira LHS 2000. Epidemiological aspects of human papillomavirus infection and cervical cancer in Brazil. J Infection 40: 80-87. 
Clifford GM, Gallus S, Herrero R, Muñoz N, Snidjers PFJ, Ferrecio C, Hieu NT, Franceschi S 2005. Worldwide distribution of human papillomavirus in cytologically normal women in IARC: a pooled-analysis. Lancet 366: 991-998.

Coutinho LMS, Scazufca M, Menezes PR 2008. Methods for estimating prevalence ratios in cross-sectional studies. Rev Saude Publica 42: 1-6.

Cuschieri KS, Cubie HA, Whitley MW, Seagar AL, Arends MJ, Moore C 2004. Multiple high-risk infections are common in cervical neoplasia and young women in a cervical screening population. J Clin Pathol 57: 68-72.

Ferenczy A, Coutlée F, Franco E, Hankins C 2003. Human papillomavirus and HIV co-infection and risk of neoplasias of the lower genital tract. A review of recent developments. Can Med Assoc J 169: 1-19.

Franco E, Villa L, Rohan T, Ferenczy A, Petzl-Erler M, Matlashewski G 1999. Desing and methods of the Ludwing-Mc Gill longitudinal study of the natural history of human papillomavirus infection and cervical neoplasia in Brazil. Pan Am J Public Health 6: 223-233.

Giuliano AP, Harris R, Sedjo RL 2002. Incidence, prevalence and clearance of type-specific HPV infections. J Infect Dis 186: 462-469.

Heilmann V, Kreienberg R 2002. Molecular biology of cervical cancer and its precursors. Curr Womens Health Rep 2: 27-33.

Ho GY, Bierman R, Beardsley L, Chang C, Burk RD 1988. Natural history of cervicovaginal papillomavirus infection in young women. N Engl J Med 338: 423-428.

INCA - Instituto Nacional de Câncer 2008. Estimativa de incidência e mortalidade por câncer no Brasil. Available from: http://www. inca.org.br.

Jones SB 1999. Cancer in developing world: a call to action. BMJ 319: 505-508.
Lepique AP, Rabachini T, Villa LL 2009. HPV vaccination: the beginning of the end of cervical cancer? A review. Mem Inst Oswaldo Cruz 104: 1-10.

Muñoz N, Kato I, Bosch FX, Eluf-Neto J, de San Jose S 1996. Risk factors for HPV detection in middle-aged women. Sex Transm Dis 23: 504-510.

Naud P, Matos J, Hammes L, Stuckzynski J, Brouwers K, Magno V, Dias E, Crusius P, Campos C, Hoblik M, Marroni R, Syrjanen K 2006. Factors predicting intermediate endpoints of cervical cancer and exposure to human papillomavirus (HPV) infections in young women screened as potential targets for prophylactic HPV vaccination in south of Brazil. Eur J Obstet Gynecol 12: 110-118.

Oliveira FA, Pleger V, Lang K, Heukelbach J, Miralles I, Fraga F, Souza AQ, Stoffler-Meilicke M, Ignatius R, Kerr LFS, Feldmeier H 2007. Sexually transmitted infections, bacterial vaginosis and candidiasis in women of reproductive age in rural Northeast Brazil: a population-based study. Mem Inst Oswaldo Cruz 102: 751-756.

Pereira CR, Rosa MLG, Vasconcellos GAL, Cavalcanti SMB, Oliveira LHS 2007. Human papillomavirus prevalence and predictors to cervical cancer among high risk women from Rio de Janeiro, Brazil. Int J Gynecol Cancer 17: 651-660.

Stern PL 2005. Immune control of human papillomavirus (HPV) associated anogenital disease and potential for vaccination. J Clin Virol 32: 48-57.

Syrjanen S, Shabalova IP, Petrovichev N 2003. Sexual habits and human papillomavirus infections smong women of three new independent states of former Soviet Union. Sex Transm Dis 30: 680-684.

Villa LL, Sichero L, Rahal P, Caballero O, Ferenczy A, Rohan T, Franco EL 2000. Molecular variants of human papillomavirus types 16 and 18 prefentially associated with cervical neoplasia. J Gen Virol 81: 2959-2968.

Wang SS, Schiffman M, Shields TS, Herrero R, Hildesheim A, Bratti $\mathrm{MCl}$ 2003. Seroprevalence of HPV 16, 18, 31 and 45 in a population-based cohort of 10,000 women from Costa Rica. Br J Cancer 89: 1248-1254. 